\title{
Creep Rates of Heat-Affected Zone of Grade 91 Pipe Welds as Determined by Stress-Relaxation Test
}

\author{
Leijun $\mathrm{Li}^{\mathrm{a}}$, Bishal Silwal ${ }^{\mathrm{b}}$, Andrew Deceuster ${ }^{\mathrm{c}}$ \\ ${ }^{a}$ Chemical 85 Materials Engineering, University of Alberta, Edmonton, Canada T6G 2V4 \\ ${ }^{b}$ Mechanical $\mathscr{B}$ Aerospace Engineering, Utah State University, Logan, Utah 84322 \\ ${ }^{c}$ Manufacturing Engineering Technology, Weber State University, Ogden, Utah 84403
}

\begin{abstract}
Cross-weld creep testing conducted at $650^{\circ} \mathrm{C}$ under $69 \mathrm{MPa}$ stress has reproduced either the Type I or Type IV failure mode in Grade 91 welds, depending on the post-weld heat treatment procedures. Welds post-weld heat treated below the $A_{C 1}$ temperature have ruptured in the Type VI failure mode, while welds heat-treated above the $A_{C 1}$ temperature of the alloy have ruptured in the Type I failure mode. Heat-treatments at lower temperatures and shorter durations have produced a reduced creep rate. The accelerated short term stress-relaxation test has been conducted to obtain the input creep rates for a finite element model for the cross-weld creep testing. The model predicted secondary creep rates are in good agreement with the results from the conventional cross-weld creep tests. From the finite element model, the creep damage by cavitation is believed to start at regions where the first principal stress and stress triaxiality concentrate.
\end{abstract}

Keywords: Grade 91, Heat-affected zone, Cross-weld Creep, Stress-relaxation, PWHT, Type IV failure

\section{Introduction}

The creep-enhanced ferritic steel Grade 91 was designed for creep service at higher temperature and stress levels than those could be provided by P22 [1]. Due to the higher design stress provided by Grade 91, a reduced section thickness would enhance the component's thermal fatigue resistance under

Email address: leijun.li@ualberta.ca (Leijun Li)

Preprint submitted to Int. J. Pressure Vessel \&3 Piping

March 30, 2015

(C) 2016. This manuscript version is made available under the Elsevier user license

http://www.elsevier.com/open-access/userlicense/1.0/ 
oxidation conditions. However, premature failures were reported in Grade 91 weldments due to creep damage in the heat-affected zone [2, 3]. In such Type IV cracking, initially reported by Shuller et al [4], creep voids form in the fine-grained and inter-critical heat-affected zone of high-Cr ferritic heat resisting steels, leading to early failure compared with creep tests on the base material [5, 6]. Openly reported creep results on Grade 91 crossweld specimens became abundant most recently, for instance, by Parker et al $[7,8,10]$ and in reviews by Abson and Rothwell [9] and David et al [11]. Data on Type IV creep failure as a function of post-weld heat-treated at various temperatures and times are in great demand $[12,11]$.

Although most of the total creep deformation comes from the fine-grained HAZ in Type IV damage of cross-weld specimens of Grade 91, some researchers have assumed the total creep strain to be additive of contributions from a composite material of base, weld and heat-affected zones. Using this additive assumption, Li, Shinozaki, and Kuroki [13] studied the coarsegrained and fine-grained heat-affected zones in a two-dimensional finite element model and concluded that the first principal stress controlled the formation of voids in Type IV failure, which agreed with previously reported conclusion. Watanabe et al [14] considered three different regions - weld metal, base metal, and fine-grained heat-affected zone - in a finite element model and concluded that the stress triaxiality controlled the creep void formation. Both studies used estimated high temperature material properties in their models, and the models did not include all regions in the heat-affected zone.

To measure the creep law from specific heat-affected zones, simulated microstructure needs to be reproduced according to the measured thermal history during the actual welding. To test the simulated specimens using conventional constant load creep testing, however, takes a long time and great cost. A short-term accelerated creep test that produces usable creep law data is desired. Yet it has to be understood that the creep rates obtained from short-term tests are derived from the current status of the material. Longterm damage such as aging, oxidation, and the interactive microstructure evolution during creep is not considered in the short-term test. Woodford showed that the creep rates could be generated from a stress relaxation test [15]. Rao et al [16] recently proved that the crest rates from stress relaxation tests with a $0.8 \%$ initial strain are in good agreement with the results from conventional creep tests for a $10 \%$ Cr cast steel. Jung et al [17] compared the data from compressive stress relaxation tests of a zirconium alloy with 
2 to $10 \%$ initial strain, and concluded that the minimum creep rates from relaxation tests matched well with the creep rates from the conventional creep tests.

This paper will study the finite element modeling of the cross-weld creep in Grade 91 joints as affected by post-weld heat-treatment (PWHT) below and above $\mathrm{A}_{C 1}$ temperature. The study will consider cross-weld creep specimens that are consisted of base metal, weld metal, and three regions of the heat-affected zone. The input data will be obtained from an accelerated creep test using the stress-relaxation method.

\section{Experimental Procedure}

\subsection{Welding and heat treatment}

The ASTM A335 P91/ASME SA335 P91 pipe had an 8.625-inch (219 $\mathrm{mm}$ ) outer diameter, 1.143-inch $(29 \mathrm{~mm})$ thickness, and was normalized for 8 minutes at $1060^{\circ} \mathrm{C}$ and tempered for 45 minutes at $786^{\circ} \mathrm{C}$ in its as-received condition. The chemical composition of the Grade 91 pipe and filler metals are given in Table 1. Two 8-inch $(203 \mathrm{~mm})$ long pipes were welded together by gas-tungsten arc welding (GTAW) and flux-cored arc welding (FCAW) processes. The double- $\mathrm{V}$ weld groove had a $60^{\circ}$ included angle with $1.5 \mathrm{~mm}$ root face. GTAW was used for the root pass with $300 \mathrm{~A}$ DC and $1.27 \mathrm{~m} / \mathrm{min}$ wire feed speed, and FCAW was used for the filling passes with $26.5 \mathrm{~V}$ arc voltage and $7.0 \mathrm{~m} / \mathrm{min}$ wire feed speed. Pure argon shielding was used for GTAW and mixed 75 Argon/25 $\mathrm{CO}_{2}$ shielding was used for FCAW. The filler metal was $1.2 \mathrm{~mm}$ diameter ER90S-B9 for GTAW, and ER91T1-B9 for FCAW. The $0.14 \mathrm{~m} / \mathrm{min}$ linear travel speed was maintained for GTAW and $0.292 \mathrm{~m} / \mathrm{min}$ for FCAW by a stepper motor controlled fixture. Sixteen Type-K thermocouples were placed on different locations from the edge of the weld groove to measure the temperature profile. Two 8-channel data loggers were used to record the temperature measurements with a sampling frequency of $5 \mathrm{~Hz}$. After welding, the locations of the thermocouples were re-measured relative to the fusion line, which was assumed to have experienced the melting temperature. The microstructure from the HAZ of the as-welded specimen was then analyzed and the HAZ locations were identified and measured from the fusion line. The interpass temperature was maintained with a use of ceramic pad heater and surface temperature probe, with an accuracy of temperature control at $\pm 10^{\circ} \mathrm{C}$. The preheat temperature was between 150 and $250^{\circ} \mathrm{C}$. The interpass temperature during welding 
Table 1: Chemical composition of Grade 91 base and filler metals (wt.\%).

\begin{tabular}{rrrr}
\hline \hline & $\begin{array}{r}\text { ER90S-B9 } \\
\text { GTAW }\end{array}$ & E91T1-B9 & FCAW \\
Fetal \\
\hline $\mathrm{C}$ & 0.097 & 0.10 & 0.11 \\
$\mathrm{Mn}$ & 0.56 & 0.79 & 0.37 \\
$\mathrm{Si}$ & 0.25 & 0.28 & 0.37 \\
$\mathrm{~S}$ & 0.004 & 0.008 & 0.002 \\
$\mathrm{P}$ & 0.006 & 0.02 & 0.016 \\
$\mathrm{Cr}$ & 8.83 & 9.1 & 8.47 \\
$\mathrm{Ni}$ & 0.307 & 0.55 & 0.08 \\
$\mathrm{Mo}$ & 0.928 & 0.88 & 0.94 \\
$\mathrm{Nb}$ & 0.064 & 0.03 & 0.071 \\
$\mathrm{~N}$ & 0.03 & 0.05 & 0.048 \\
$\mathrm{O}_{2}$ & $47 \mathrm{ppm}$ & & \\
$\mathrm{Ti}$ & 0.001 & & \\
$\mathrm{Al}$ & 0.002 & 0.001 & 0.002 \\
$\mathrm{~V}$ & 0.197 & 0.2 & 0.19 \\
$\mathrm{Cu}$ & 0.013 & 0.04 & \\
$\mathrm{As}$ & 0.003 & 0.002 & \\
$\mathrm{Sn}$ & 0.003 & 0.008 & \\
$\mathrm{Sb}$ & 0.003 & 0.002 & \\
$\mathrm{~B}$ & 0.0007 & & \\
$\mathrm{Zr}$ & 0.001 & & \\
$\mathrm{CO}$ & 0.028 & & \\
$\mathrm{Ca}$ & 0.003 & & \\
$\mathrm{Ta}$ & 0.001 & & \\
$\mathrm{~W}$ & 0.005 & & \\
$\mathrm{H}$ & $3 \mathrm{ppm}$ & & \\
\hline \hline
\end{tabular}


was between 200 and $300^{\circ} \mathrm{C}$. A pneumatic descaler and wire brushing were used for slag removal. A post-weld bake out at $250^{\circ} \mathrm{C}$ temperature for 4 hours was conducted with temperature-controlled oven. Subsequently, the

as-welded joints were post-weld heat-treated in an air furnace with a heating rate of $10^{\circ} \mathrm{C} /$ minute, holding for 2 or 8 hours at various temperatures both below and above the $A_{C 1}$, and air cool to room temperature.

\subsection{Creep test}

The cross-weld creep specimens were extracted from the welded and heattreated pipe samples as shown in Figure 1a. The dog-bone shaped creep specimen had an effective gauge length of $84 \mathrm{~mm}$ and a $8.8 \times 12.7 \mathrm{~mm}$ crosssection (Figure 1b). The creep test was a constant load type at temperature and stress of $650^{\circ} \mathrm{C}$ and $69 \mathrm{MPa}$ respectively. The temperature inside the furnace was maintained at $650^{\circ} \mathrm{C}$ with a fluctuation of $\pm 1.7^{\circ} \mathrm{C}$. Two strain gauges were placed in the front and rear sides of the specimen and average strain was recorded as a function of time in successive time increment until rupture.

\subsection{Stress-relaxation test for Stage II creep rates}

A finite element model for the cross-weld creep test was developed. As critical inputs, the Stage II creep rates for each of the weld regions were required. To identify these input parameters, this study employed an accelerated creep test method based on the stress-relaxation testing. In a stressrelaxation test, the total strain $\left(\epsilon_{t}\right)$ in the specimen is kept constant, but the total strain consists of the elastic part $\epsilon_{e}$ and plastic (i.e., creep $\epsilon_{c}$ ) part, $\epsilon_{t}=\epsilon_{e}+\epsilon_{c}$. During the relaxation test, the stress in the specimen decreases because of the plastic strain increases at the expense of the elastic strain while the total strain remains unchanged $[15,19]$. As the stress is relaxed, an ever slower plastic strain rate will be observed in the specimen, eventually the strain rate will be as slow as in the typical creep rate regime (e.g., $\left.10^{-9} / \mathrm{sec}\right)$. The recorded stress $(\sigma)$ vs. time $(t)$ data from the relaxation test can be differentiated in time to give the creep strain rate $\left(\dot{\epsilon}_{c}\right)$, according to

$$
\dot{\epsilon}_{c}=\frac{d \epsilon_{c}}{d t}=-\frac{1}{\mathrm{E}}\left(\frac{d \sigma}{d t}\right)
$$

where $\mathrm{E}$ is modulus of elasticity at test temperature.

The errors in creep rates determined in this way may be due to temperature non-uniformity in the Gleeble heating method, but more likely may be 


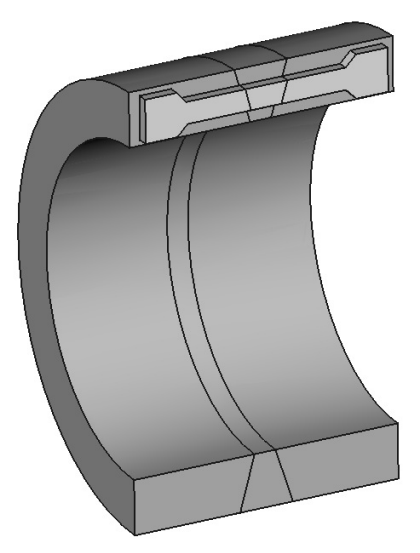

(a)
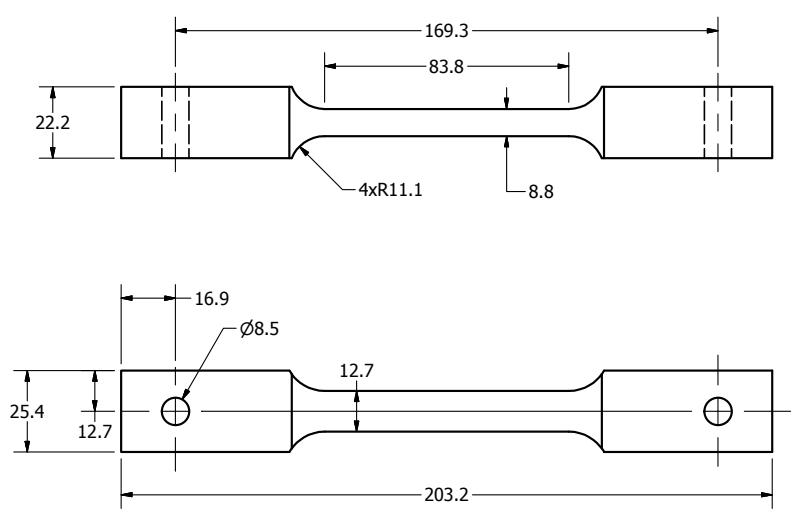

(b)

Figure 1: Schematic of cross-weld creep test specimen extraction from the welded pipe (a), and the dimensions of the creep rupture specimen (in $\mathrm{mm}$ ) (b). 
due to the differences in the loading and damage modes of the two tests: In the constant displacement stress-relaxation test, the creep damage is always decelerating; In the constant load creep test, the creep damage is always accelerating. Also, because the stress-relaxation test covers a few days of time, during which the specimen would not have undergone the long-term microstructure aging under conventional creep. Therefore, we would propose to use the stress-relaxation as an accelerated test method to obtain a ranking of creep resistance in alloy selection, alloy design, or selection of manufacturing procedures, such as post-weld heat-treatment.

Three heat-affected zone regions (CGHAZ, FGHAZ and ICHAZ), weld metal (WM), and base metal (BM) were heat-treated at various temperatures in a furnace. To make a specimen out of a narrow HAZ region, $10 \times 10 \mathrm{~mm}$ square bar made of the base metal was simulated on the Gleeble to duplicate the actual measured thermal cycle for the HAZ region. The detailed test procedure for the microstructure simulation can be found elsewhere [18]. Each of the prepared materials was then machined into $10 \mathrm{~mm}$ by $10 \mathrm{~mm}$ square bars $150 \mathrm{~mm}$ long. A reduced cross sectional area, that was $5.3 \mathrm{~mm}$ by $5.3 \mathrm{~mm}$ and $50.8 \mathrm{~mm}$ in length, was machined at the center of these samples. On the Gleeble 1500D, the gauge length (span between the fixtures) of the specimen was $50 \mathrm{~mm}$ for all tests gripped between stainless sample fixtures. Using the stainless fixture helped to minimize the temperature difference along the span of specimen. The surface temperature difference, measured by multiple thermocouples, between the middle of the span and $1 \mathrm{~mm}$ to the edge of the span was $10^{\circ}$ for the $650^{\circ} \mathrm{C}$ long-time tests, when the entire test system reached it thermal equilibrium. The specimen was heated in the Gleeble "load-control" mode at $100^{\circ} / \mathrm{min}$ to $650^{\circ} \mathrm{C}$ with loading set to zero. Once the temperature was reached, it was held for 5 minutes, then the system was switched to "L-strain control" mode. In the strain control mode, the L-strain was first zeroed, and then followed by applying an $1 \%$ strain to the specimen. During the 48-hour relaxation test, the temperature and strain were held constant, while the stress was recorded at a frequency of 0.5 $\mathrm{Hz}$.

Following testing, the recorded stress versus time data were curve fit to a polynomial function by a non-linear regression analysis. The smoothed stress function was then differentiated numerically against time according to Equation 1 to get the strain rate results. A plot of logarithmic strain rate $\dot{\epsilon}_{c}$ 
versus stress $\sigma$ resulted in the Norton law:

$$
\dot{\epsilon}_{c}=A \sigma^{n}
$$

where $A$ and $n$ are parameters specific to the test specimen. It was these Norton parameters that were used as creep constitutive inputs in the finite element model for the cross-weld creep test.

\section{Experimental Results}

The creep-rupture curves for cross-weld specimens that have undergone various PWHT procedures are shown in Figure 2. Included for comparison is also the creep curve of the base metal. All cross-weld specimens have shown decreased rupture times and increased creep strains compared with the base metal. Within the heat-treatment temperature range covered in this study, a general trend is that a lower temperature PWHT (lower than $760^{\circ} \mathrm{C}$ ) results in a longer rupture time and a lower creep rate; a heat-treatment temperature higher than $820^{\circ} \mathrm{C}$ results in a shorter rupture time and significantly greater creep strain (Table 2). This trend seems to suggest that to enhance the creep properties, a lower post-weld heat-treatment temperature should be used. Yet it must be reminded that the impact toughness of the heat-affected zone recovers only after a heat-treatment at $740^{\circ} \mathrm{C}$ [18]. We believe that is the basis for the recommended $760^{\circ} \mathrm{C}$ optimum post-weld heat-treatment temperature by the codes. Although the differences in creep lives may not be significant, the test data do show the creep rupture life for the specimen PWHT at $760^{\circ} \mathrm{C}$ to be shorter than the specimen PWHT at $820^{\circ} \mathrm{C}$. While it is puzzling that the "recommended" $760^{\circ} \mathrm{C}$ PWHT fails to produce the longest creep life, it may be helpful to point out the recommended $760^{\circ} \mathrm{C}$ cannot be optimum for every particular steel. The $A_{C 1}$ for the steel in this study is $820^{\circ} \mathrm{C}$; so the best PWHT temperature may be around $800^{\circ} \mathrm{C}$. Another aspect to compare the results is to look at the total creep strain. A PWHT at $760^{\circ} \mathrm{C}$ does produce a smaller creep strain (and a smaller creep rate) than the $820^{\circ} \mathrm{C}$ PWHT.

The minimum creep rates for specimens heat treated at lower temperatures can be as low as that of the base metal, yet the creep rupture time is curtailed by at least $50 \%$ (comparing $600^{\circ} \mathrm{C}-2 \mathrm{~h}$ specimen and the base metal). These lower temperature heat-treated specimens ruptured in the heat-affected zone, in so called Type IV failure mode. A closer inspection of 
the tested specimens reveals that the creep deformation concentrated in the narrow HAZ, so that $1 \%$ total creep strain across the specimen gauge length almost entirely occurred in a region narrower than $1 \mathrm{~mm}$ (Figure 3). The wedge shaped weld metal did not show much creep deformation, but slided along the HAZ line as a whole. As will be shown later, we believe such localized severe deformation promotes triaxial stress status for cavity formation. The Type IV failure mode leads to early failure because the creep damage attacks the weakest link (i.e., the fine-grained and inter-critical HAZ) of the cross-weld specimen. Post-weld heat-treatment at $820^{\circ} \mathrm{C}$ and above produced cross-weld specimens to rupture with a large creep ductility and significantly shortened rupture time (Table 2). Inspections of tested specimens reveal that these specimens ruptured at the weld metal, in so called Type I failure mode. Another significant change is that the creep strain distributed evenly across the weld metal and HAZ, although the final rupture happened near the center line of the weld.

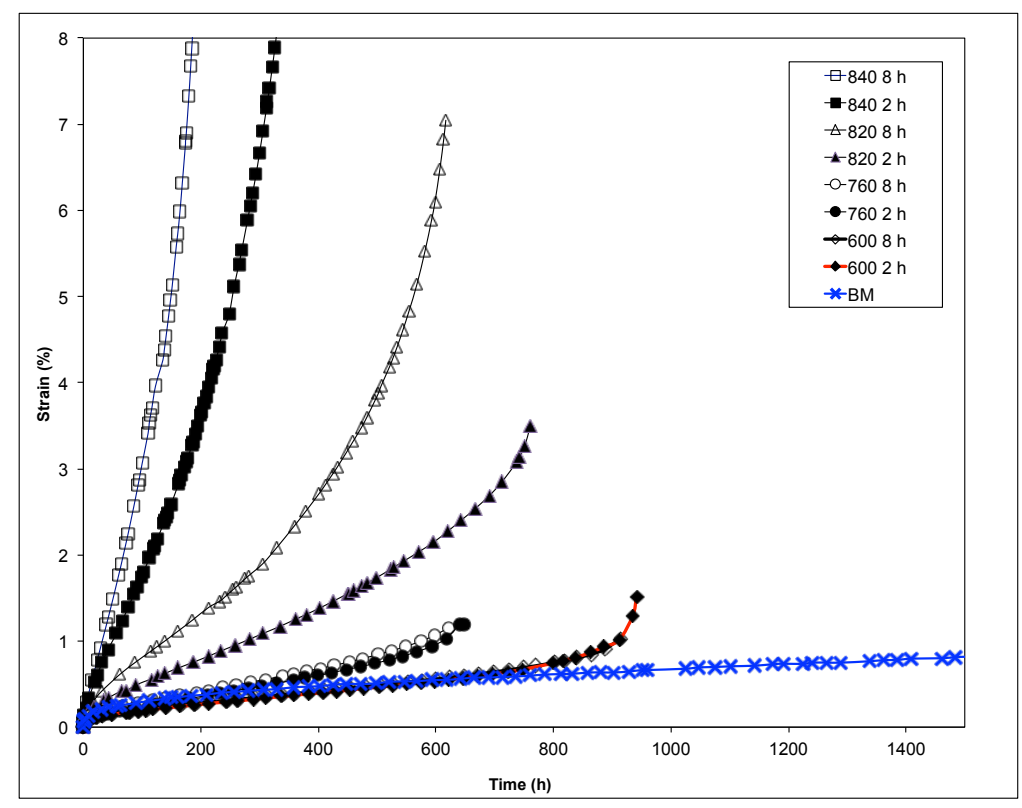

Figure 2: Creep strain of cross-weld specimens tested at $650^{\circ} \mathrm{C}$ and $69 \mathrm{MPa}$. The specimens were post-weld heat treated at various temperatures for 2 or 8 hours.

The effect of heat-treatment time on creep rupture of cross-weld specimens seems to be insignificant for heat-treatment at temperatures lower than $760^{\circ} \mathrm{C}$ (Table 2 ). A small decrease of $4.3 \%$ was observed in rupture time for 


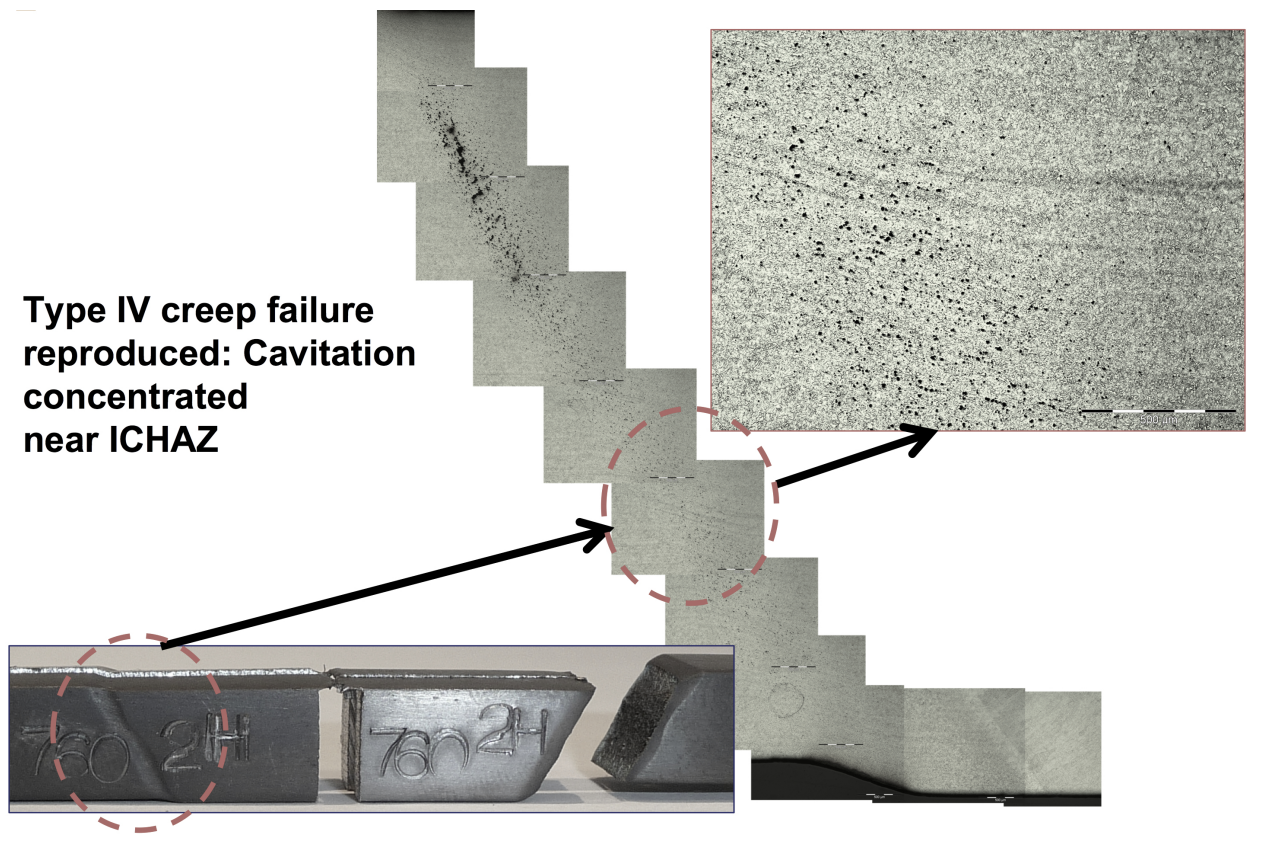

Figure 3: The cross-weld specimen heat treated at $760^{\circ} \mathrm{C}$ for 2 hours ruptured in the intercritical heat-affected zone (ICHAZ), with the creep strain occuring in a narrow band, in which shear deformation and cavitation concentrate.

Table 2: Creep rupture time $\left(t_{R}\right)$, total creep strain $\left(\epsilon_{R}\right)$, and average strain rate $\left(\dot{\epsilon}_{\text {avg }}\right)$ from creep tests of cross-weld specimens following various post-weld heat-treatment procedures.

\begin{tabular}{lllll}
\hline \hline PWHT $\left({ }^{\circ} \mathrm{C}-\mathrm{h}\right)$ & $\mathrm{t}_{R}(h)$ & $\epsilon_{R}(\%)$ & $\dot{\epsilon}_{\text {avg }}\left(\frac{\%}{h}\right)$ & Rup. location \\
\hline $600-2$ & 942 & 1.5 & $1.6 \mathrm{E}-3$ & HAZ \\
$600-8$ & 925 & 1.0 & $1.1 \mathrm{E}-3$ & HAZ \\
$760-2$ & 649 & 1.2 & $1.8 \mathrm{E}-3$ & HAZ \\
$760-8$ & 621 & 1.1 & $1.9 \mathrm{E}-3$ & HAZ \\
$820-2$ & 760 & 3.4 & $4.5 \mathrm{E}-3$ & HAZ \\
$820-8$ & 617 & 7.0 & $1.1 \mathrm{E}-2$ & Weld \\
$840-2$ & 388 & 15.4 & $4.0 \mathrm{E}-2$ & Weld \\
$840-8$ & 205 & 14.3 & $7.0 \mathrm{E}-2$ & Weld \\
Base Metal & 2402 & 1.0 & $4.2 \mathrm{E}-4$ & Test terminated \\
\hline \hline
\end{tabular}


8-hour heat-treatment compared with the 2-hour heat-treatment at $600^{\circ} \mathrm{C}$. At heat-treatment temperatures close to or higher than the lower critical temperature $A_{C 1}$ (measured by dilatometry to be $820^{\circ} \mathrm{C}$ for the test material), however, significant increases in creep strain and decreases in rupture time were observed. A $47.2 \%$ decrease was observed in rupture time for 8hour heat-treatment compared with the 2 -hour heat-treatment at $840^{\circ} \mathrm{C}$. For the $820^{\circ} \mathrm{C}\left(A_{C 1}\right)$ heat-treatment, a 2-hour hold time resulted in the Type IV failure in the HAZ, and an 8-hour hold time resulted in the Type I failure in the weld metal.

\section{Secondary Creep Rate in Cross-weld Specimens}

Each microstructure region in the cross-weld specimen has different material properties. To understand how each region responds to creep loading, a finite-element model is developed to calculate the secondary creep rates. The length of each microstructure region was measured in each cross weld specimen under a microscope. The measured length of the cross-weld specimen consisted of the base metal (BM), heat-affected zone (HAZ), and weld metal (WM):

$$
L_{C W}=L_{B M}+L_{H A Z}+L_{W M}
$$

The heat-affected zone was further subdivided into coarse-grained (CGHAZ), fine-grained (FGHAZ), and inter-critical (ICHAZ):

$$
L_{H A Z}=L_{C G H A Z}+L_{F G H A Z}+L_{I C H A Z}
$$

The cross-weld creep strain was assumed to be additive, therefore, the crossweld creep rate $\left(\dot{\epsilon}_{C W}\right)$ was approximated by:

$$
\begin{array}{r}
\dot{\epsilon}_{C W}=\dot{\epsilon}_{B M} \frac{L_{B M}}{L_{C W}}+\dot{\epsilon}_{W M} \frac{L_{W M}}{L_{C W}}+\dot{\epsilon}_{C G H A Z} \frac{L_{C G H A Z}}{L_{C W}}+ \\
+\dot{\epsilon}_{F G H A Z} \frac{L_{F G H A Z}}{L_{C W}}+\dot{\epsilon}_{I C H A Z} \frac{L_{I C H A Z}}{L_{C W}}
\end{array}
$$

We developed an ANSYS finite-element model for the measured crossweld sample geometry (Figure 4). The measured thickness of inter-critical heat-affected zone (ICHAZ) was $0.3 \mathrm{~mm}$, fine-grained zone (FGHAZ) was 0.7 $\mathrm{mm}$, coarse-grained zone (CGHAZ) was $1.0 \mathrm{~mm}$, and the total HAZ length 


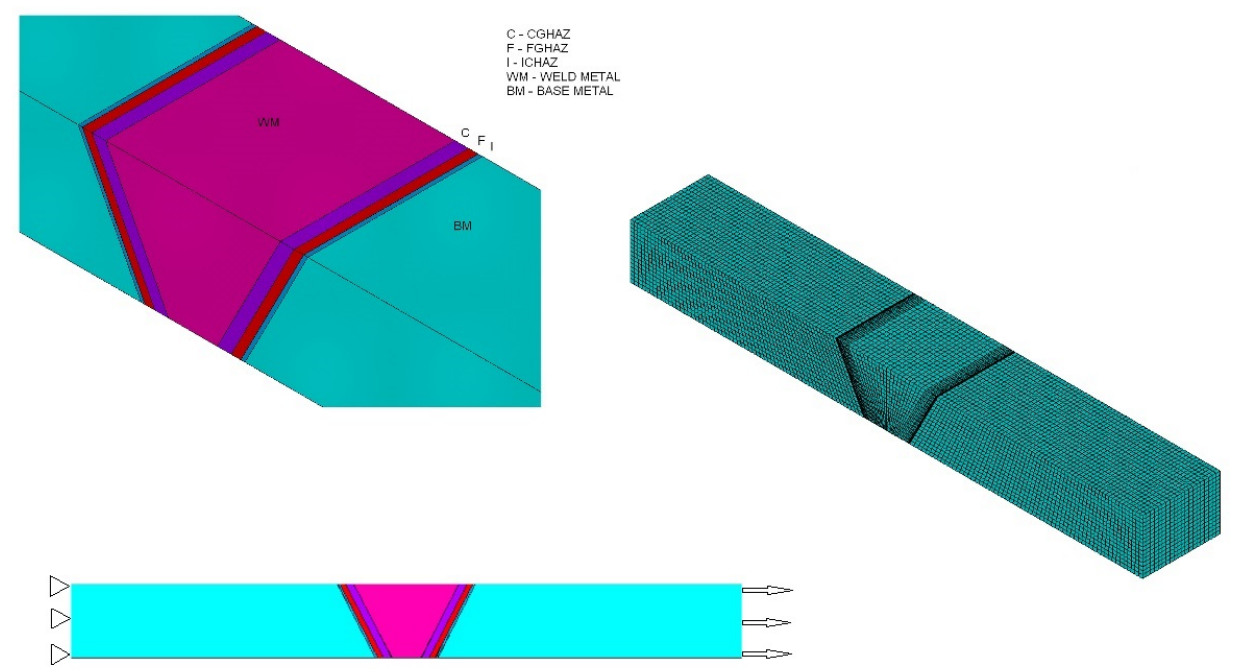

Figure 4: Finite element model representing geometry, mesh and boundary condition

was $2.0 \mathrm{~mm}$. The SOLID185 element type with eight nodes and three degrees of freedom at each node was used. This type of element had creep, plasticity, stress stiffening, large deflection and large strain nonlinearity capabilities [20]. The model was meshed into 59,619 nodes and 53,120 elements. A refined mesh was used in the heat-affected zone of the specimen to increase the spatial resolution for the interested regions. A mesh study was conducted to find a mesh size at which there were no changes in model results with further mesh refinement. A fixed boundary condition for displacement was applied at the left end, and a $69 \mathrm{MPa}$ stress was applied at the right end of the gauge length (Figure 4). A uniform temperature of $650^{\circ} \mathrm{C}$ was applied to the model.

The creep law for the primary creep stage of the model was obtained from the actual creep tested curves using a curve fitting algorithm in ANSYS. Since the primary creep is only a very small fraction of the total rupture time, such usage of primary creep law had been proved effective in creep models [13]. We applied the same primary creep law (Equation 6) to all cross-weld regions for a given specimen. 


$$
\epsilon_{p}=\frac{C_{1} \sigma^{C_{2}} t^{C_{3}+1}}{C_{3}+1}
$$

where $C_{1}, C_{2}$, and $C_{3}$ are constant parameters fit to a given specimen.

The secondary creep was modeled by the Norton law as described in (Equation 2). The constants obtained from the short term stress-relaxation test were input as material properties for the cross-weld specimens as outlined in the Experimental Procedure.

The modulus of elasticity was measured for the $\mathrm{HAZ}$ regions, weld metal, and base metal at $650^{\circ} \mathrm{C}$ on the Gleeble (Table 3). Following a $760^{\circ} \mathrm{C}$ heattreatment, the coarse-grained and fine-grained heat-affected zones have a higher modulus, while the base metal, inter-critical HAZ, and weld metal have a lower modulus. The inter critical HAZ has the lowest modulus at $650^{\circ} \mathrm{C}$ following a $760^{\circ} \mathrm{C}$ heat-treatment. After heat-treatment at $820^{\circ} \mathrm{C}$ and $840^{\circ} \mathrm{C}$, the modulus of all material regions elasticity became similar at $650^{\circ} \mathrm{C}$. A correlation seems to exist between the modulus and Type IV creep behaviour, with regions with a lower modulus showing a greater creep deformation.

Table 3: Modulus of elasticity ( $\mathrm{MPa})$ tested at $650^{\circ} \mathrm{C}$ from various microstructure constituents in the Grade 91 joint. These constituents were heat-treated at different PWHT temperatures.

\begin{tabular}{lrrr}
\hline \hline Constituents & $760{ }^{\circ} \mathrm{C}$ & $820^{\circ} \mathrm{C}$ & $840{ }^{\circ} \mathrm{C}$ \\
\hline CGHAZ & 26615 & 14429 & 12645 \\
FGHAZ & 25394 & 13572 & 11606 \\
ICHAZ & 9491 & 12840 & 12096 \\
WM & 10242 & 13400 & 12745 \\
BM & 14193 & 14587 & 14128 \\
\hline \hline
\end{tabular}

The constant values of $A$ and $n$ for Norton's creep law, $\dot{\epsilon}=A \sigma^{n}$, from the stress-relaxation test of specimens treated at different post-weld heat-treating temperatures for 2 hours are given in Table 4.

Figure 5a shows the cross-weld creep deformation vs. time for both the experimental and finite element analysis for the specimen heat-treated at $760^{\circ} \mathrm{C}$ for 2 hours. The maximum difference between the model predictions and experimental results is $8 \%$ at the end of secondary creep stage. A plot of equivalent creep strain (Figure 5b) from the finite element model clearly 


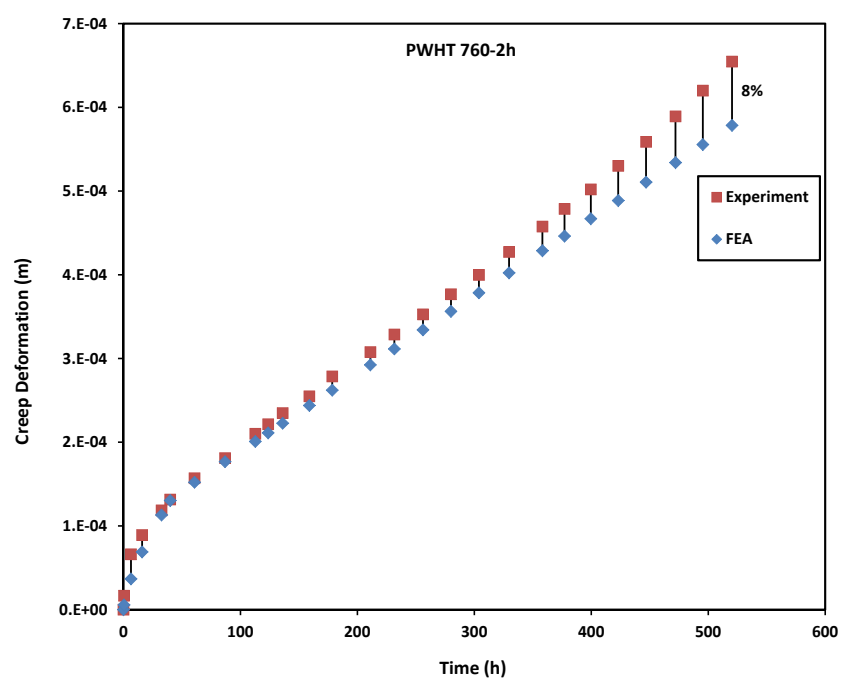

a
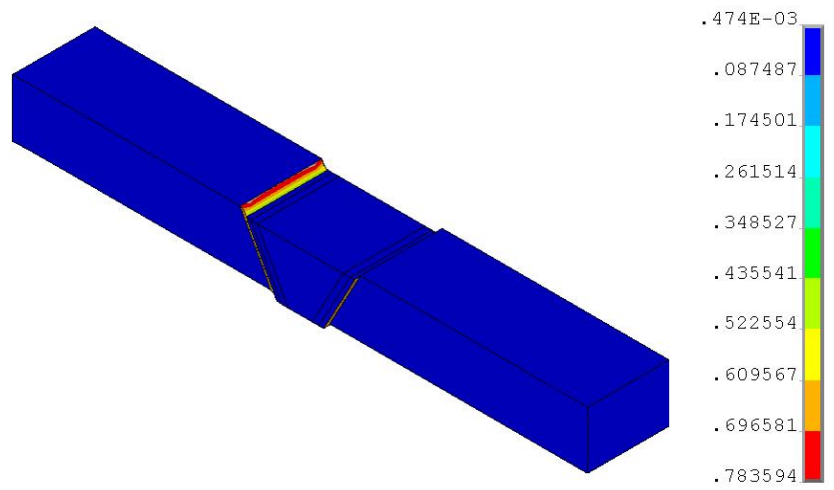

$\mathrm{b}$

Figure 5: Comparison of experiment and finite element results: (a) Creep deformation against time, (b) Equivalent creep strain at the end of secondary creep (specimen heattreated at $760^{\circ} \mathrm{C}$ for 2 hours). 


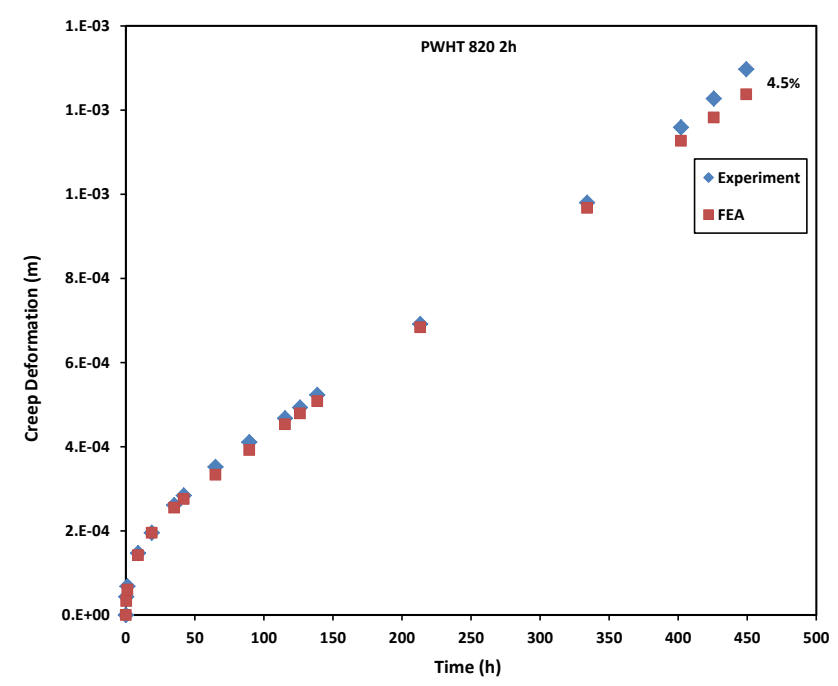

a
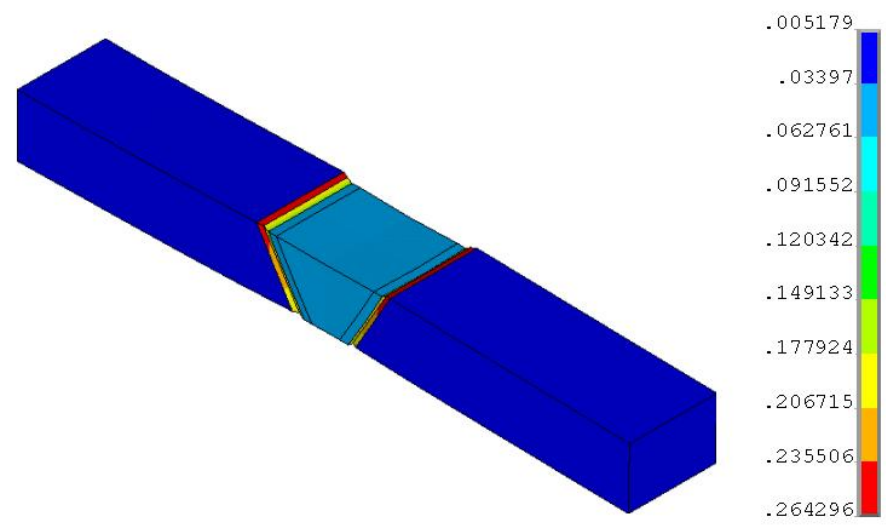

$\mathrm{b}$

Figure 6: Comparison of experiment and finite element results: (a) Creep deformation against time, (b) Equivalent creep strain at the end of secondary creep (specimen heattreated at $820^{\circ} \mathrm{C}$ for 2 hours). 
Table 4: Norton parameters, $A\left(\mathrm{MPa}^{-n} \mathrm{~s}^{-1}\right)$ and $n$, identified from stress-relaxation tests of various microstructure constituents in the Grade 91 joint. These constituents were heat-treated at different PWHT temperatures for 2 hours.

\begin{tabular}{lllllll}
\hline \hline & PWHT & BM & WM & CGHAZ & FGHAZ & ICHAZ \\
\hline$\underline{A}$ & $760{ }^{\circ} \mathrm{C}$ & $5 \mathrm{E}-28$ & $2 \mathrm{E}-30$ & $1 \mathrm{E}-50$ & $8 \mathrm{E}-33$ & $2 \mathrm{E}-33$ \\
& $820{ }^{\circ} \mathrm{C}$ & $2 \mathrm{E}-19$ & $1 \mathrm{E}-20$ & $2 \mathrm{E}-28$ & $7 \mathrm{E}-23$ & $2 \mathrm{E}-17$ \\
& $840{ }^{\circ} \mathrm{C}$ & $3 \mathrm{E}-20$ & $1 \mathrm{E}-17$ & $1 \mathrm{E}-23$ & $6 \mathrm{E}-17$ & $2 \mathrm{E}-16$ \\
\hline$\underline{\mathrm{n}}$ & $760{ }^{\circ} \mathrm{C}$ & 10 & 11 & 21 & 13 & 14 \\
& $820^{\circ} \mathrm{C}$ & 5 & 7 & 11 & 8 & 5 \\
& $840{ }^{\circ} \mathrm{C}$ & 5 & 6 & 7 & 5 & 5 \\
\hline \hline
\end{tabular}

indicates that the highest creep strain has occurred at the inter-critical heataffected zone (ICHAZ). The Type IV failure mode for the specimen, in which the weld metal shears along the heat-affected zone as a wedge as shown in Figure 3, has been correctly predicted by the model.

For the specimen heat-treated at $820^{\circ} \mathrm{C}$ for 2 hours, the cross-weld creep deformation vs. time for both the experimental and finite element analysis is shown in Figure 6a. The maximum difference between the model predictions and experimental results is $4.5 \%$ at the end of secondary creep stage. A plot of equivalent creep strain (Figure 6b) from the finite element model indicates that the highest creep strain is still at the inter-critical heat-affected zone (ICHAZ). The Type IV failure mode for the specimen, in which the weld metal shears along the heat-affected zone as a wedge, has been correctly predicted by the model.

For the specimen heat-treated at $840^{\circ} \mathrm{C}$ for 2 hours, the cross-weld creep deformation vs. time for both the experimental and finite element analysis is shown in Figure 7a. The maximum difference between the model predictions and experimental results is $11 \%$ at the end of secondary creep stage. A plot of equivalent creep strain (Figure 7b) from the finite element model indicates that a high creep strain is at both the center of the weld metal and the intercritical heat-affected zone (ICHAZ). The maximum creep strain occurred at the center of the weld metal, in which creep rupture was observed in the experiment (Table 2). So the Type I failure mode for the specimen heattreated at $840^{\circ} \mathrm{C}$ for 2 hours has also been correctly predicted by the model. 

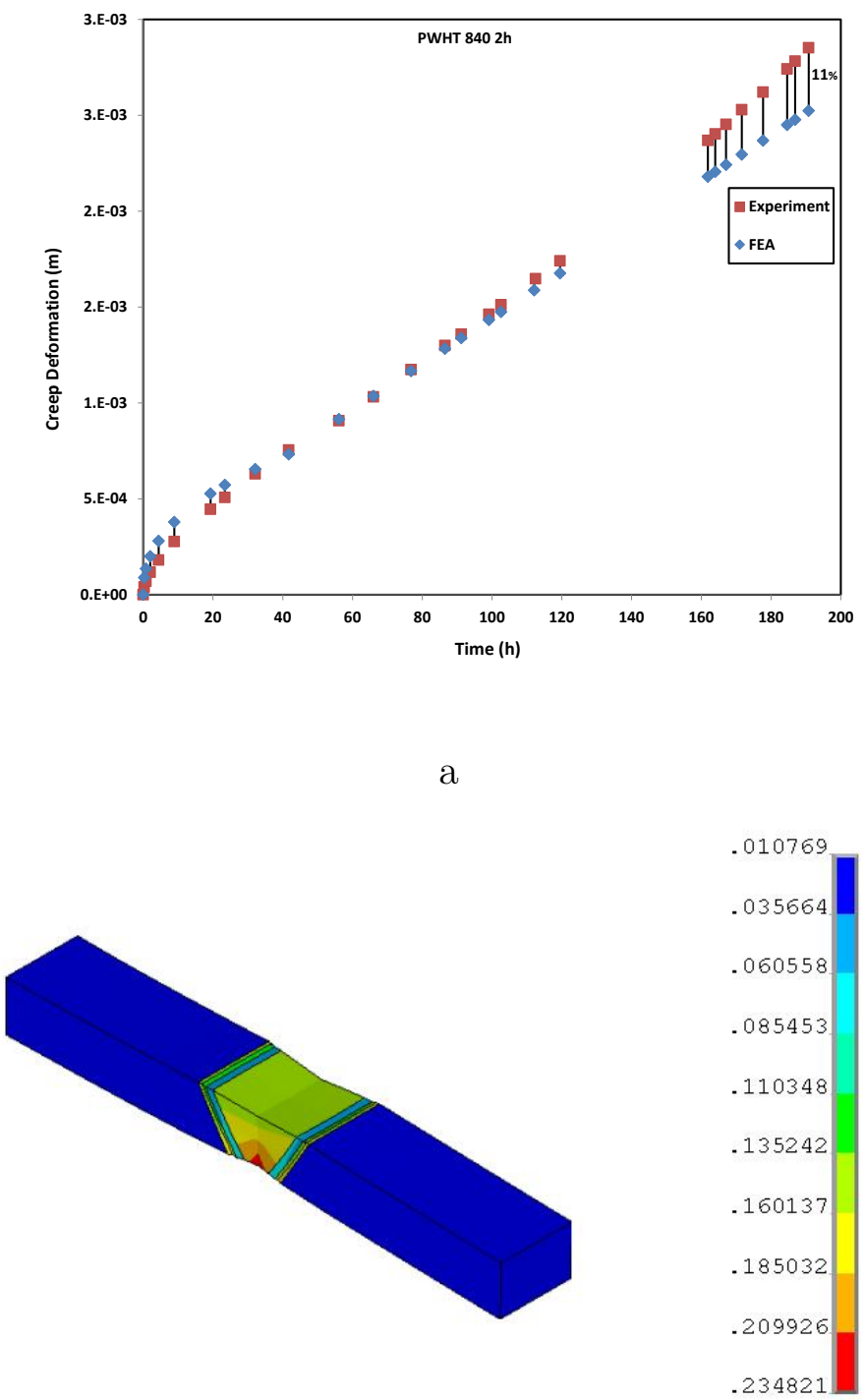

$\mathrm{b}$

Figure 7: Comparison of experiment and finite element results: (a) Creep deformation against time, (b) Equivalent creep strain at the end of secondary creep (specimen heattreated at $840^{\circ} \mathrm{C}$ for 2 hours). 


\section{Discussion}

The fidelity of a finite element model depends on the accuracy of the input material properties. While most of the published creep models for cross-weld specimens would use estimated creep laws for various microstructure regions, we have used measured values from an accelerated creep test. To validate the stress-relaxation test as a viable method for the secondary creep rates, we tested, under stress-relaxation, the same batch of cross-weld specimens that were tested by conventional creep. The results shown in Figure 8 give the same ranking of specimens for creep performance compared with the conventional creep test results. However, only a fraction of time was spent to obtain the same ranking using the stress-relaxation method.

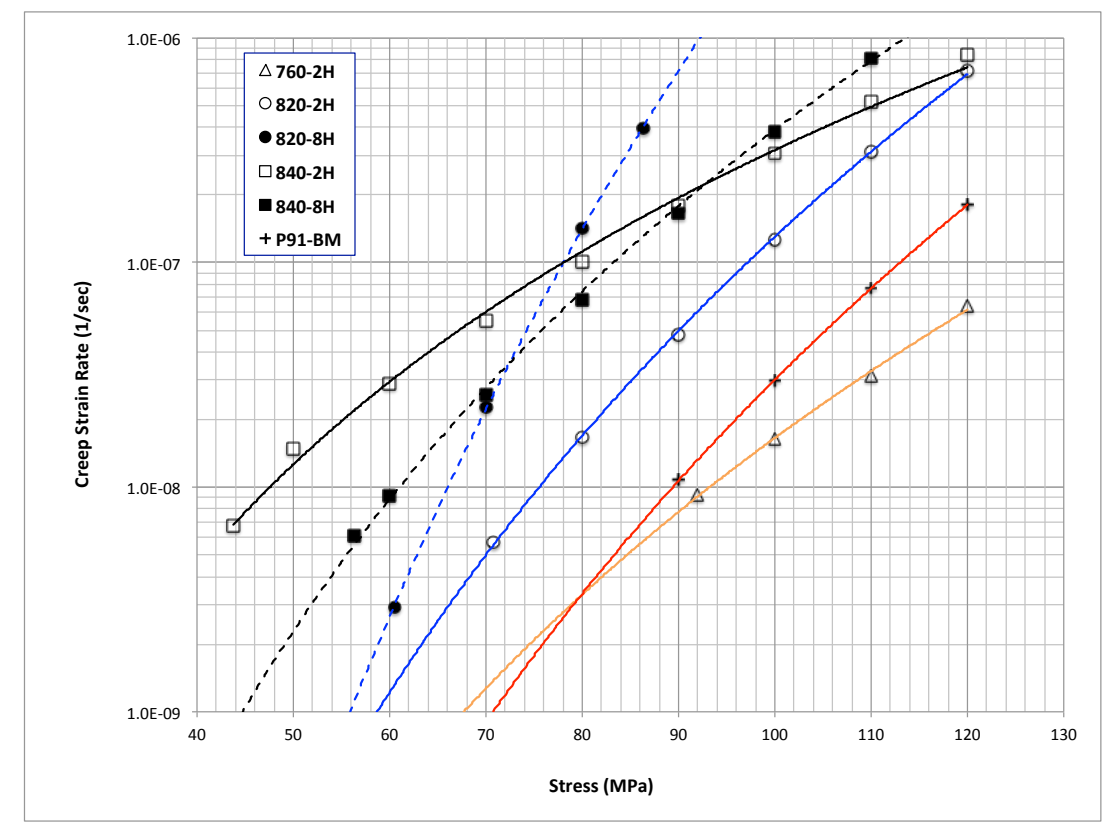

Figure 8: Stress relaxation test at $650^{\circ} \mathrm{C}$ showing the creep strain rate as a function of stress for cross-weld specimens.

In terms of accuracy, a direct comparison of minimum creep rates between conventional creep testing and stress relaxation testing is given in Table 5 . For the homogeneous base metal, the results from stress-relaxation and conventional creep tests agree within $5 \%$ of difference. For the cross-weld specimens, the stress-relaxation method seems to consistently give a lower creep 
Table 5: Comparison of minimum creep rate data from conventional creep testing and stress relaxation testing at $650^{\circ} \mathrm{C}$. The conventional creep tests were conducted at a constant stress of $69 \mathrm{MPa}$; the stress-relaxation tests were conducted at a constant $1 \%$ total strain.

\begin{tabular}{lrr}
\hline \hline Material & Creep $\dot{\epsilon}_{\min }(1 / \mathrm{sec})$ & Relaxation $\dot{\epsilon}_{\min }(1 / \mathrm{sec})$ \\
\hline Base metal & $8.33 \mathrm{E}-10$ & $8.79 \mathrm{E}-10$ \\
$760 \mathrm{C}-2 \mathrm{H}$ & $3.61 \mathrm{E}-09$ & $1.50 \mathrm{E}-09$ \\
$820 \mathrm{C}-2 \mathrm{H}$ & $8.33 \mathrm{E}-09$ & $5.10 \mathrm{E}-09$ \\
$820 \mathrm{C}-8 \mathrm{H}$ & $1.39 \mathrm{E}-08$ & $1.30 \mathrm{E}-08$ \\
$840 \mathrm{C}-2 \mathrm{H}$ & $4.17 \mathrm{E}-08$ & $5.50 \mathrm{E}-08$ \\
$840-8 \mathrm{H}$ & $7.22 \mathrm{E}-08$ & $1.50 \mathrm{E}-08$ \\
\hline \hline
\end{tabular}

rate, but still within 5 to $50 \%$ of differences from the conventional creep tested rates. The differences may have been due to temperature non-uniformity in the Gleeble heating method, but more likely may be due to the differences in the loading and damage modes of the two tests: In the constant displacement stress-relaxation test, the creep damage is always decelerating; In the constant load creep test, the creep damage is always accelerating. Also, because the stress-relaxation test covers a few days of time, during which the specimen would not have undergone the long-term microstructure aging under conventional creep. Therefore, we would propose to use the stress-relaxation as an accelerated test method to obtain a ranking of creep resistance in alloy selection, alloy design, or selection of manufacturing procedures, such as post-weld heat-treatment. For better comparison, selected conventional creep tests should be conducted to calibrate the stress-relaxation tests for a given material. For instance, if we increase the stress relaxation test results in Table 5 by $30 \%$, we will be able to estimate the creep rates to $10 \%$ accuracy of the conventional creep test results. As demonstrated in this study, the stress-relaxation method also seems to be valid for obtaining secondary creep rates input data for creep simulations.

The stress-strain conditions that lead to Type IV failure mode in the cross-weld specimens can be analyzed using the developed creep model. Figure 9 shows the stress distributions along the center line of the cross-sectional view of the specimens. These are snapshots of the stress distributions at the end of the secondary creep stage for each specimen. It is apparent that the 
distribution of equivalent stress does not correlate with the creep strain and damage distribution. At the inter-critical HAZ, where the Type IV damage is maximum, the equivalent stress is at minimum. The frequently used Huddleston stress [14] does not correlate well with the observed creep damage either. However, the first principal stress is found to correlate with the creep damage accurately. The stress triaxiality factor defined as

$$
\frac{\sigma_{I}+\sigma_{I I}+\sigma_{I I I}}{\sigma_{e}}
$$

where $\sigma_{I}, \sigma_{I I}$, and $\sigma_{I I I}$ are first, second, and third principal stresses, and

$\sigma_{e}$ is the equivalent stress, has also been found to indicate accurately the location of creep strain and cavitation damage. For the case of specimen heat treated at $840^{\circ} \mathrm{C}$, the actual fracture location was in the weld metal (Type I failure). Both first principal stress and stress triaxiality indicate two maximum locations, one in the inter-critical HAZ, the other in the weld metal (Figure 9c). Although the creep rupture happened in the weld metal, the inter-critical HAZ also have developed some significant creep cavitation, as evidenced in Figure 10.

\section{Conclusions}

Cross-weld creep testing conducted at $650^{\circ} \mathrm{C}$ under $69 \mathrm{MPa}$ stress has reproduced either the Type I or Type IV failure mode in Grade 91 welds, depending on the post-weld heat treatment procedures. Welds post-weld heat treated below the $A_{C 1}$ temperature have ruptured in the Type VI failure mode, while welds heat-treated above the $A_{C 1}$ temperature of the alloy have ruptured in the Type I failure mode. Heat-treatments at lower temperatures and shorter durations have produced more superior creep properties.

The accelerated short term stress-relaxation test has been conducted to obtain the input creep rates for a finite element model for the cross-weld creep testing. The model predicted secondary creep rates are in good agreement with the results from the conventional cross-weld creep tests. It is observed that the equivalent creep strain can predict the failure location of the crossweld specimen. The first principal stress and stress triaxiality are found to be good indicators for creep void formation and prediction parameters for the failure location. 

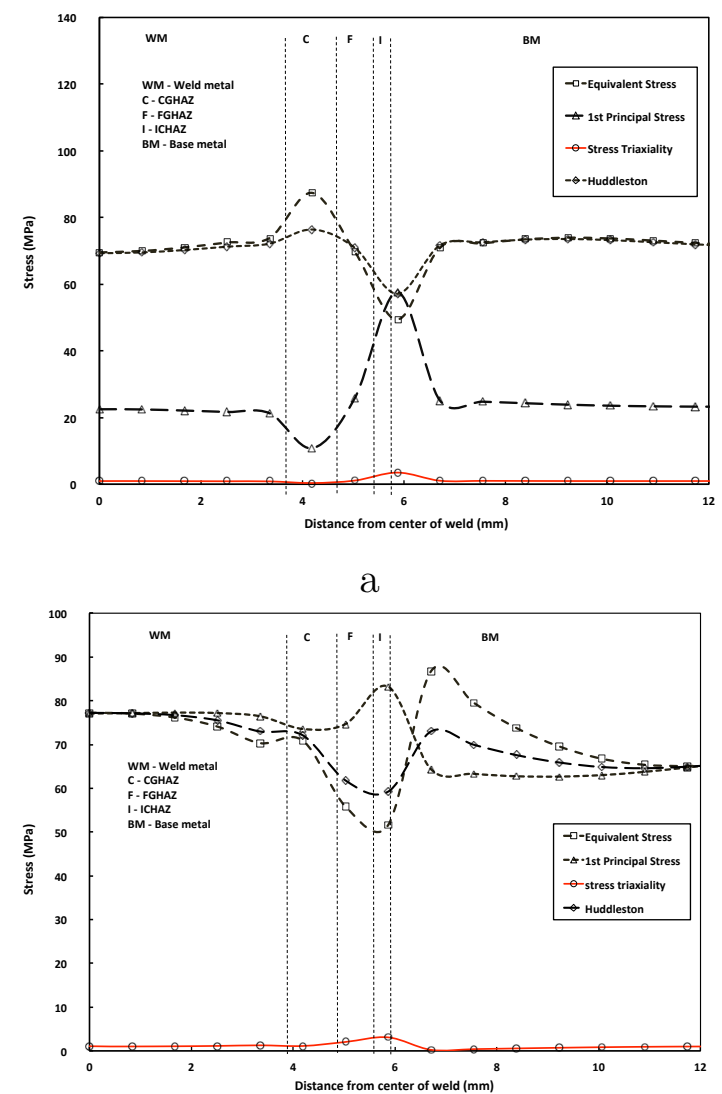

$\mathrm{b}$

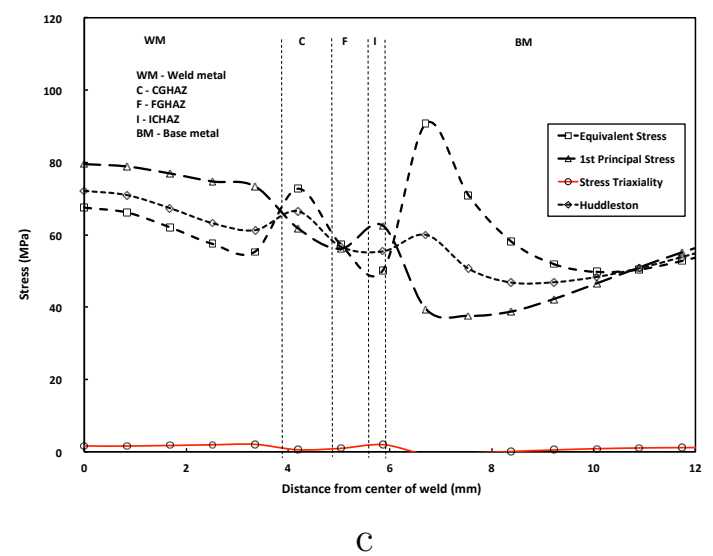

Figure 9: Stress distribution at the end of secondary creep for (a) PWHT at $760^{\circ} \mathrm{C}$ for 2 hours, (b) PWHT at $820^{\circ} \mathrm{C}$ for 2 hours, and (c) PWHT at $840^{\circ} \mathrm{C}$ for 2 hours. 

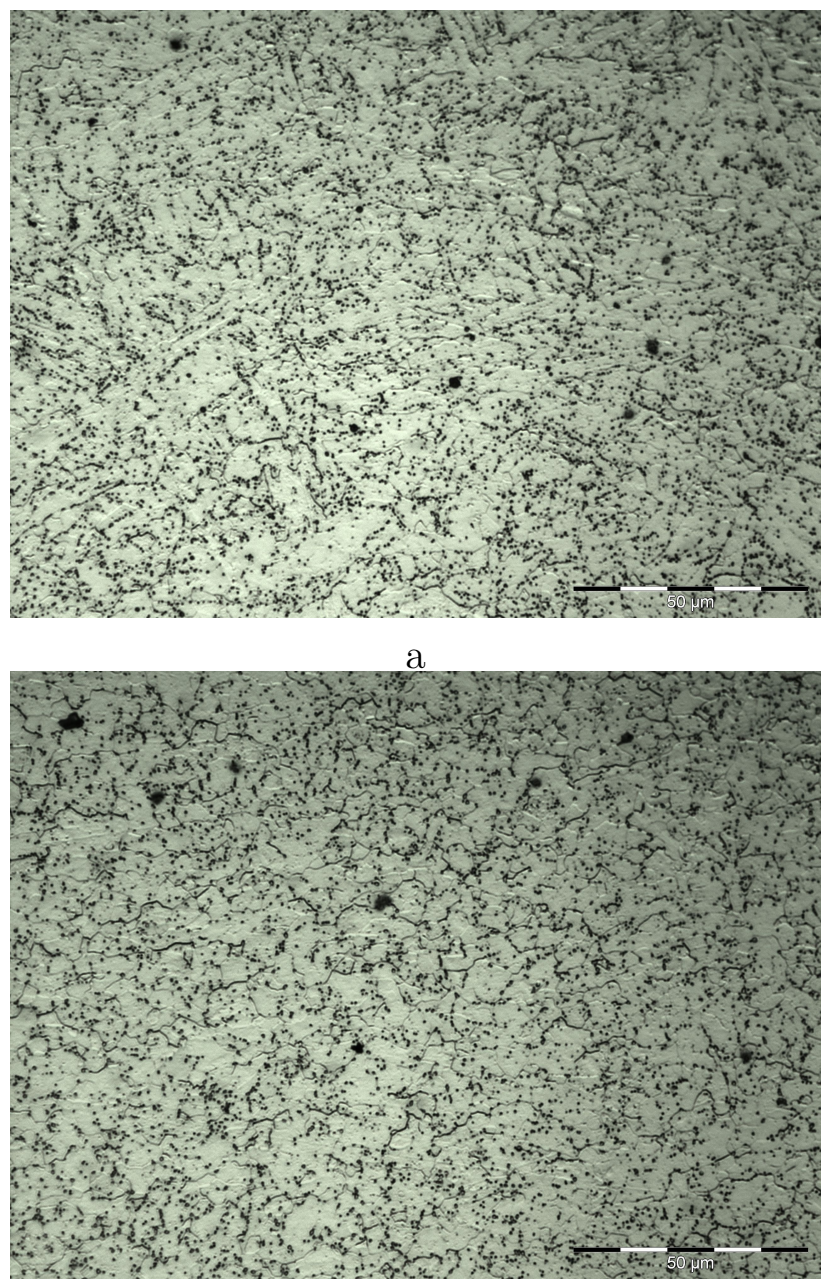

$\mathrm{b}$

Figure 10: Microstructure of creep tested specimen heat-treated at 840C. (a) cavity in the weld metal, (b) cavity in the inter-critical heat-affected zone. 


\section{Acknowledgment}

This work has been sponsored by the U.S. Department of Energy through its Nuclear Engineering University Program (NEUP).

\section{References}

[1] Sikka, V.K., Ward, C.T. and Thomas, K.C., "Modified 9Cr-1Mo steelan improved alloy for steam generator application", Ferritic Steels for High-Temperature Applications, Proceedings of the ASM International Conference on Production, Fabrication Properties, and Applications of Ferritic Steels for High Temperature Applications. Metals Park, Ohio, USA: American Society for Metals (1983), 65-84.

[2] Gaffard, V., Gourgues-Lorenzo, A. F., and Besson, J., "High Temperature Creep Flow and Damage Properties of $9 \mathrm{Cr} 1 \mathrm{MoNbV}$ Steels: Base Metal and Weldment." Nuclear Eng. \& Design, 235 (2005), 2547-2562.

[3] Shibli, A., Starr, F., 2007, "Some aspects of plant and research experience in the use of new high strength martensitic steep P91", International J. Pressure Vessels \& Piping, 84 (2007), 114-122.

[4] Shuller, H. J., Hagan, L., and Woitschek, A., "Cracks in the weld area of formed parts in superheated steam lines - material analysis", Der Maschinenschaden, 1 (1974), 1-13.

[5] Tabuchi, M., Watanabe, T., Kubo, K., Matsui, M., Kinugawa, J., and Abe, F., "Creep crack growth behavior in the HAZ of weldments of W containing high Cr steel", International J. Pressure Vessels \& Piping, 78(11) (2001), 779-784.

[6] Francis, J.A., Mazur, W., Bhadeshia, H.K.D.H., "Review: Type IV cracking in ferritic power plant steels", Materials Sci. \& Tech., 22 (2006), $1387-1395$.

[7] Parker, J., "Factors affecting Type IV creep damage in Grade 91 steel welds", Materials Sci. \& Eng. A, 578 (2013) 430 - 437.

[8] Parker, J. and Brett, S. "Creep performance of Grade 91 header", International J. Pressure Vessels \& Piping, 111-112(2013), 82-88. 
[9] Abson, D.J. and Rothwell, J.S., "Review of type IV cracking of weldments in 9-12\% Cr creep strength enhanced ferritic steels", International Materials Reviews, (2013) 58(8), 437-473.

[10] Parker, J., "In-service behaviour of creep strength enhanced ferritic steels Grade 91 and Grade 92 - Part 2 weld issues", International J. Pressure Vessels \& Piping, 114-115(2014), 76-87.

[11] David, S.A., Siefert, J.A., and Feng, Z., "Welding and weldability of candidate ferritic alloys for future advanced ultra supercritical fossil power plants", Science \& Technology of Welding and Joining, (2013) 18(8), 631-651.

[12] Li, L., "Effect of Post-Weld heat-treatment on Creep Rupture Properties of Grade 91 Steel Heavy Section Welds - Final Report," 09-799, Reactor Concepts RD\&D, DOE - NEUP (2012).

[13] Li, D., Shinozaki K, and Kuroki H, "Stress-strain analysis of creep deterioration in heat affected weld zone in high $\mathrm{Cr}$ ferritic heat resistant steel", Mater Sci \& Technol, (2003) 19, 1253-1260.

[14] Watanabe, T., Tabuchi, M., Yamazaki, M., Hongo, H., and Tanabe, T. "Creep damage evaluation of $9 \mathrm{Cr} 1 \mathrm{MoVNb}$ steel welded joints showing Type IV fracture." International J. Pressure Vessels \& Piping, (2006)83(1), 63-71.

[15] Woodford, D. A., "Creep analysis of Zircaloy-4 and its application in the prediction of residual stress relaxation." J. Nuclear Materials, (1979) 79, 345-353.

[16] Rao, G. R., Gupta, O. P., and Pradhan, B., "Application of stress relaxation testing in evaluation of creep strength of a tungsten-alloyed 10\% Cr cast steel." International J. Pressure Vessels \& Piping, (2011) $88,65-74$.

[17] Jung, Y-I., Seol, Y-N., Choi, B-K., and Park, J-Y., "Behavior of stress relaxation and the estimation of creep in $\mathrm{Zr}-1.1 \mathrm{Nb}-0.05 \mathrm{Cu}$ alloy." Materials \& Design, (2012) 42, 118-123. 
[18] Silwal, B., Li, L., Deceuster, A., and Griffiths, B., "Effect of post-weld heat treatment on toughness of heat-affected zone of Grade 91 steel." Welding J., (2013) 92, 80-87.

[19] Li, L., and Messler, R. W. Jr., "Stress relaxation study of heat-affected zone reheat cracking in Type 347", Welding J., (2000) 79(6), 136s-144s.

[20] ANSYS, Inc. "Documentation for ANSYS." 